\title{
A cognitive analysis of Proverbs 1:20-33
}

\begin{tabular}{|c|c|}
\hline \multicolumn{2}{|c|}{$\begin{array}{l}\text { Author: } \\
\text { Pieter M. Venter }{ }^{1} \mathbb{0}\end{array}$} \\
\hline \multicolumn{2}{|c|}{$\begin{array}{l}\text { Affiliation: } \\
\text { 'Department Old Testament } \\
\text { Studies, Faculty of Theology } \\
\text { and Religion, University } \\
\text { of Pretoria, Pretoria, } \\
\text { South Africa }\end{array}$} \\
\hline \multicolumn{2}{|c|}{$\begin{array}{l}\text { Research Project Registration: } \\
\text { Project Leader: P.M. Venter } \\
\text { Project Number: } 02350106\end{array}$} \\
\hline \multicolumn{2}{|c|}{$\begin{array}{l}\text { Description: } \\
\text { This research is part of the } \\
\text { project, 'Old Testament } \\
\text { Apocrypha, Pseudepigrapha } \\
\text { and Qumran Texts Studies' } \\
\text { directed by Prof. Pieter } \\
\text { Venter, Emeritus Professor, } \\
\text { Department of Old Testament } \\
\text { Studies, Faculty of Theology, } \\
\text { University of Pretoria. }\end{array}$} \\
\hline \multicolumn{2}{|c|}{$\begin{array}{l}\text { Corresponding author: } \\
\text { Pieter Venter, } \\
\text { profpmventer@gmail.com }\end{array}$} \\
\hline \multicolumn{2}{|c|}{$\begin{array}{l}\text { Received: } 05 \text { Sept. } 2018 \\
\text { Accepted: } 09 \text { Feb. } 2019 \\
\text { Published: } 15 \text { May } 2019\end{array}$} \\
\hline \multicolumn{2}{|c|}{$\begin{array}{l}\text { How to cite this article: } \\
\text { Venter, P.M., 2019, 'A } \\
\text { cognitive analysis of Proverbs } \\
\text { 1:20-33', HTS Teologiese } \\
\text { Studies/Theological Studies } \\
\text { 75(4), a5257. https://doi.org/ } \\
\text { 10.4102/hts.v75i4.5257 }\end{array}$} \\
\hline \multicolumn{2}{|c|}{$\begin{array}{l}\text { Copyright: } \\
\text { (c) 2019. The Authors. } \\
\text { Licensee: AOSIS. This } \\
\text { is licensed under the } \\
\text { Creative Commons } \\
\text { Attribution License. }\end{array}$} \\
\hline \multicolumn{2}{|l|}{ Read online: } \\
\hline 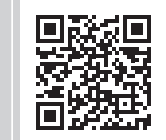 & $\begin{array}{l}\text { Scan this QR } \\
\text { code with your } \\
\text { smart phone or } \\
\text { mobile device } \\
\text { to read online. }\end{array}$ \\
\hline
\end{tabular}

This article uses cognitive linguistics and an embodied cognitive approach to analyse the passage of Proverbs 1:20-33. The poem, presented as a prophetic threat, uses metaphoric language to depict the dialogue between personified wisdom and metaphorised human beings. The analysis indicates that there is a coherence of metaphors in the target domain shared by both metaphorised source domains of wisdom and the hearers. Using bodily metaphors it stresses the need of wisdom to be internalised by men.

Keywords: Cognitive analysis; Metaphoric language; Lady wisdom; Proverbs 1; Poem.

\section{The intricate composition of Proverbs 1:20-27}

The passage consists of an introduction $(\operatorname{Pr} 1: 20-21)$ and a speech $(\operatorname{Pr} 1: 22-31)$. The quoted address in Proverbs 1:22-31 consists of three strophes: 1:22-25, 1:26-27 and 1:28-33. There is an inverted symmetry (inclusio) between the first and last strophe, a type of 'inverse return' (Fox 2008:101). Wisdom's appeal to listen is reversed when wisdom rejects the hearers because they do not listen to her. These strophes form a mirror-like frame for the central strophe in Proverbs 1:26-27. Although the correspondence between these two strophes is 'sometimes too vague to form exclusive links' (Fox 2008:104), the inverted structure is reflected in the central strophe of Proverbs 1:26-27. This strophe shows a 'conspicuous structural feature' (Loader 2014:87). It is chiastically arranged in the Masoretic Text. Directly translated verse 26 reads: and I in your calamity (A) will laugh (B); I will mock you (B) when comes your disaster (A). This scheme is inverted in verse 27 : when comes like a storm (C) your disaster (A); and your calamity (A) like a whirlwind (C); and when comes over you (A) distress and anguish (C). This arrangement reflects the reversal and chiastic organisation of the first and last strophes.

\section{Cognitive linguistics and metaphorical communication}

Language operates in a larger context than mere linguistic constructions. It has a communicative function that has to be studied as well. People communicate with each other in a specific time, within a specific cultural context, under specific circumstances and according to the unspoken rules active among members of society. Proverbs 1:20-27 should, therefore, also be studied within this larger context.

Jindo (2009:222) investigates the connection between language, culture and cognition in antiquity. He uses cognitive linguistics as tool to study this field. The 'cognitive linguistic account of metaphor' (Jindo 2009:225) points out that all communications are metaphorical. There are two domains in communication. Both are conceptual. In the first domain, the source domain, 'metaphorical verbal expressions' (Jindo 2009:226) are used to conceptualise that which is visible in everyday life. The other conceptual domain is called the target domain. When these two conceptual domains are understood in terms of one another, there is a 'conceptually integrated configuration' (Jindo 2009:226) - a metaphoric conceptual coordination. When 'the constituent conceptual elements of the source domain correspond to the constituent elements of the target domain' (Jindo 2009:227), 'mapping' can take place, outlining the juxtaposition of the two conceptual domains.

Lakoff (followed by Mark Johnson, Mark Turner and Rafael E. Núñez) developed his version of cognitive linguistics during the 1970s. According to Lakoff and Johnson (2003:7), 'the human conceptual system is metaphorically structured and defined'. One kind of thing is always understood in terms of another. Our apprehension of well-known physical objects, actions and situations (such as containers, spaces and trajectories) is used to apprehend other 'more complex domains (such as mathematics, relationships or death)' (Embodied cognition). Metaphors are used from the speaker's known world to conceptualise an item. This metaphor then operates as a conduit in communication. The hearer takes the idea or objects out of the word or containers (cf. Lakoff \& Johnson 2003:10). 
Several types of metaphors are used as conduits. Some are structural, others orientational and still some others ontological. According to Lakoff and Johnson (2003:152153), our experiences (orientational, ontological and structural) may cause conventional metaphors. Orientational and ontological metaphors enable structural variety of conventional metaphors. New metaphors are usually structural. Coming from our constant interaction with our physical and cultural environments (cf. Lakoff \& Johnson 2003:120), new metaphors trivialise our experiences, hiding some aspects but highlighting others.

Metaphor-forming is neither static nor isolated. Metaphors are open-ended, imaginative and creative. Concepts verbalised in the form of metaphors are interactional. When a second metaphor serves the same purpose of understanding an aspect of the concept, there is an overlap, forming 'cross-metaphorical correspondences' (Lakoff \& Johnson 2003:98). This coincides with what Jindo (2009:226) calls 'conceptually integrated configuration', a metaphoric conceptual coordination. Lakoff and Johnson (2003:118) call this coherence of metaphors 'experiential gestalt'. These Gestalts represent 'coherent organizations of our experiences in terms of natural dimensions' (Lakoff \& Johnson 2003:118).

All of these metaphors have the body as the base of all cognition. The 'body is an indispensable epistemic source' (Viviers 2005:889). '[E]mbodied cognitive science' (Tschacher \& Scheier 2001:555) indicates that cognition is not restricted to the organism's internal entities, working only with abstract thought (cf. Wilson 2002:625). Mankind's sensorimotor capacities enable him or her to 'extend beyond abstract conceptualizations' (Harquail \& King 2010:1620). The body stands central in the cognitive process when the organism is interacting with its environment. Embodied cognition means that a person interacts with his or her environment in terms of his or her sensorimotor capabilities, and continually constructs and construes concepts accordingly. The situations in which the cognitive process is activated can comprise four categories: 'bodily-kinesthetic, visual-spatial, temporalaural, and emotional' (Harquail \& King 2010:1623).

Next to the view of the body as epistemic source, different views on the body as object are also used. The body is then seen as a container. It has its confines but also has the capability of receiving and presenting. This in-out orientation is projected onto other objects that are also bounded by surfaces, and who can also receive and present objects. We, therefore, talk of the body as container with an inside and an outside.

Jindo's (2009:224) aim is to develop a 'methodological model for a systematic and empirical analysis'. According to Jindo, the exegete has to follow three steps to map the correspondence between the source and the target conceptual domain. Firstly, the images and expressions in the source domain are to be investigated on conceptual level. The second step is to relate the two domains organically coordinating them on conceptual level. As metaphor intends 'systematic correspondences between two conceptual domains' (Jindo 2009:228), each domain is to be approached holistically. The third step is to clarify and extend the conceptual information in the source domain linking it to ancient culture. These steps are now followed to analyse the passage in Proverbs 1:20-33.

\section{An embodied cognitive analysis of Proverbs 1:20-33}

The 'sapiential discourse' (Loader 2014:89) in Proverbs 1:20-33 lends itself to an embodied cognitive analysis. The speaker in the source domain (wisdom personified as a living prophet) addresses a metaphorical group of people by using several conduit metaphorical phrases. The sensory-motor action of speech is used by wisdom, metaphorising her thoughts. Although the hearers are not quoted, their sensory action is depicted in metaphorical terms as well. They hear what is spoken, experience disaster, start acting at a certain stage and call upon wisdom. They form a second source domain in dialogue with the first source domain of wisdom speaking. These two source domains share the same target domain. The way the speaker is depicted in metaphorical terms stands in correlation with the way the hearers are portrayed. This is indicated by the chiastic structure of the strophes in the passage. What is more, the metaphors used for the speaker (wisdom) are all explicated in terms of the metaphors for the hearers, and vice versa - see the repetition of terms in the first and third strophe. Wisdom is what wisdom is in terms of who or what the addressees are. They are who they are in terms of the metaphors for wisdom. The mutual target domain is the contents of the communication passed on by the metaphorically expressed wisdom and the metaphorically pictured hearers. There is, therefore, a coherence of metaphors, a 'conceptually integrated configuration' (Jindo 2009:226) and an 'experiential gestalt' (Lakoff \& Johnson 2003:118).

Some features in the text aid in conceptualising the domains. In the Hebrew Bible, people are portrayed by their acts rather than their appearance. People are who they are in terms of the depiction of their deeds. The typical Semitic use of poetic parallelism (parallelismus membrorum) between lines also helps us in identifying the concepts in both source domains. The poetic parallelism used in the passage corresponds with what Lakoff and Johnson (2003:128) call 'metaphorical spatialization of language'. Poetic iteration (repetition) by using parallel phrases stretches (spatialise) the metaphoric intention. The repeated categorisation of the object indicates an extension of the metaphorical interactive purpose of the communication. The chiastic structures found in the passage enhance the inherent systematicness between the poetic lines. What is more, the chiastic structure between the different sections of the passage corroborates the reversal of orientation. Wisdom's willingness to reach out turns about to unwillingness to no longer take any initiative. Wisdom closes its ranks to the plea of the hearers. When disaster strikes, the hearers suddenly change their inward orientation and reach out to wisdom, but with no avail. They are even willing to accept something from outside - eat the fruit of their ways (1:31). But they remain in their catastrophic state. 
The metaphorical terms used for both parties are mainly ontological metaphors. Wisdom is depicted as a person, a typical prophet of Israel, someone acting in public. Her performance agrees with that of the prophetic speeches of Jeremiah (cf. Jer 7 and 20) and of Zechariah (Zch 7). There are numerous similarities in diction and phrasing. The parallel is also rather thematic (cf. Fox 2008:105). Wisdom gets hands, feet and a mouth to personally urge the hearers to save themselves. Like a prophet, she condemns the unresponsive audience with the authority of God. Personification is an ontological metaphor par excellence to depict a nonhuman entity (wisdom) in terms of human characteristics (cf. Lakoff \& Johnson 2013:35). The metaphorical expressions used in wisdom's source domain indicate public action, reaching out to hearers, disappointment with their reaction, wisdom's scorn and threats to be no longer available to them. Wisdom offers what is metaphorically depicted as teachings, rebuke, advice and thoughts. This is, furthermore, a special case of structural metaphor, namely, metonymy (synecdoche) (cf. Lakoff \& Johnson 2003:37). Each of the entities mentioned focuses upon certain aspects of a larger whole (cf. Lakoff \& Johnson 2013:38). By using a wide variety of metaphorical human actions, the passage depicts different aspects of the speaker wisdom.

According to Lakoff and Johnson (2003:41), '[c]ultural and religious symbolism are special cases of metonymy'. What wisdom offers is much more than just teachings and advice. It is a way of life. When wisdom stretches out its metaphorical hand ${ }^{1}$ and gives something the addressees can accept, absorb and internalise, a comprehensive system is meant. It is an invitation to a systematic correlation with wisdom's essence. The 'repent' of 1:23 is an orientational metaphor that gives the order of opening up to wisdom. ${ }^{2}$ Wisdom invites the addressees to break out of their inner circular movement and open up to wisdom, to move outside of themselves. They are to break away from their complacency, their self-satisfaction and create some spatialisation outside of themselves. However, wisdom does exactly what they do: she speaks her

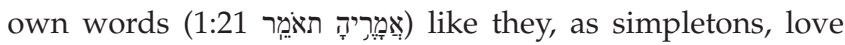
their own simple ways, are mockers who delight in their own

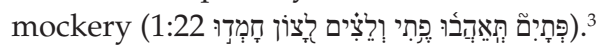

The use of chiasmus indicates a simultaneous change of itinerary by both parties. Both wisdom and the hearers change direction. However, there is a difference in the results of their turnaround. As result of the hearer's negative reaction, wisdom changes its orientation. ${ }^{4}$ Wisdom's reaction to their wayward behaviour is spatial - metaphorically depicted as withdrawal. She no longer reaches out, but

1.Loader (2014:96) discusses the meaning of reaching out the hand. Outstretched hand is parallel to give instruction, advice and invite. It is a positive gesture.

2.Fox does not understand the verb šub to mean 'return' or 'move back', whether physically or metaphorically. The preposition I- ('to') indicates the place or a person towards which one turns. 'In other words, in this verse, tašubu is not a call to repentance, but rather a call to attention' (Fox 2008:98-99)

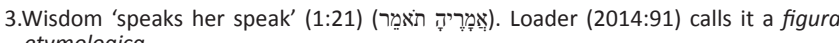
etymologica.

4.Loader (2014:97) calls it 'a poetic turning of the tables', 'Schadenfreude' (cf. also Fox 2008:101). retracts into herself, observing from a distance what takes place with the addressees. The fools showed contempt for wisdom by rejecting her advice; now she will likewise show them contempt by rejecting them. Retribution takes place and the hearers reap what they sowed. In terms of retributive justice's eye for an eye and tooth for a tooth, they ignored wisdom's call and now wisdom pays them back by also ignoring them. They are the ones who now reach out like wisdom did, but their extending of hands to wisdom is as futile as her reaching out to them was.

There are also some obvious differences. There is a fine line between the movements of wisdom and addressees. When changing direction, wisdom keeps to be in a superior position. The motor movement of wisdom laughing and mocking, looking down upon the addressees' calamity, does not drive her into the same type of passivity. Wisdom's withdrawal rather confirms her sovereignty in opposition to the hearer's futile efforts. The emotions of personalised wisdom are related to other concepts that have to do with well-being in opposition to the addressees' calamity. Lakoff and Johnson (2003:19) make the general remark regarding this type of metaphors: 'There is an overall external systematicity among the various spatialization metaphors, which defines coherence among them'.

In terms of Lakoff and Johnson's thinking, the speaker wisdom is a container with an in-out orientation. In the passage, wisdom moves out of its container and reaches out towards the addressees. What is experienced in the visual field of wisdom is other containers that also have an in-out orientation. These containers can also move in and out. The collective body of the hearers can also take in something. A 'corporeal exchange' or 'mutual incorporation' (Viviers 2005:880) can take place when wisdom's regulatory body is internalised in the bodies of the hearers. What wisdom presents moving out of its container is something the addressees can receive and take into themselves. Initially, wisdom's in-out orientation is projected upon the addressees wanting them to receive what it presents. Wisdom wants them to turn to wisdom and open up to it. Wisdom uses its mental capacities and emotional makeup to interact with the addressees, evaluating them in terms of wisdom's conceptual system and expectation. However, they are depicted as doing right the opposite.

Not only wisdom is depicted in personified terms, but also the addressees are conceptualised in terms of persons who represent a specific tendency. Although the hearers are human beings and their depiction is not personification per se, they are also pictured in metaphorical terms. They are a metaphoric characterisation of a specific cognitive condition. The hearers represent a social group and are also containers (cf. Lakoff \& Johnson 2003:60, 61, 118). They are 'entities bounded by a surface' (Lakoff \& Johnson 2003:26). They also have an in-out orientation. Wisdom incites them to move out of themselves and opens up to wisdom and takes in what she offers them. Wisdom insists on an 'openness to wisdom's message' (Fox 2008:105). Its words are to be absorbed. However, at this stage they retreat into passiveness. They draw back into their 
own containers - the direct opposite of what wisdom does when she reaches out. They keep to what they deem as their comfort zone. They are, therefore, reprimanded for staying within themselves, not being willing to open up to wisdom's call. Disastrous circumstances force them to change and to open up to wisdom. However, when they do turn to wisdom, wisdom is not willing to reach out to them any longer. Where wisdom's calling was aimed at benefiting the addressees, their calling is now purely for their own advantage. ${ }^{5}$ They are now stuck in the calamity that comes over them. Structural metaphors are used to describe what happens to them. There is an 'internal systematicity' (Lakoff \& Johnson 2003:18) in these events, creating a coherence between them. Only certain aspects of disaster and calamity are stressed, and metaphorical adversity in general rather than specific forms of disaster is intended.

The type of metaphors used for the addressees are ontological: they are depicted in terms of their aversion to wisdom's outreaching orientation. They are 'entities or substances of a uniform kind' (Lakoff \& Johnson 2003:26). They rather represent a type of reaction than persons with specific names. Based on the 'basic domain of experience' (Lakoff \& Johnson 2003:118), the metaphors used form structured wholes within recurrent human experiences. With their perceptual, motor activity, and purposive properties, they are multidimensional Gestalts of what the speaker experiences when meeting people like these. Their conduct is metaphorically seen as selfobsessed. It is conceptualised as self-destructive foolishness. Their attitude is one of being obstinate, of having excessive complacency. They are not seen in terms of prototypical fools, but rather in terms of their interaction with wisdom. The people addressed are not inherently simple ones, mockers and fools, but rather what they are in terms of their questionable interaction with wisdom. At first this personified attitude is marked by passiveness. Narcissism discourages any responsive action. The nexus between deed and consequence is, however, arranged chronologically. The deedlessness is linked to catastrophe as result. Forced by calamity this attitude turns into willingness to attend to wisdom, but this is misjudged compliance based on miscalculation and egocentricity. What exactly will happen to them is not described in detail, but rather metaphorically depicted in terms of misfortune that hits them (storm and whirlwind). The forces that will hit the object containers will come from outside and move upon their bodies bringing shame to them. Their reaction to the call of wisdom caused these disasters to come upon them. This intrusion forces them to move out of the body. The conduit of their actions are metaphorical words for searching-not finding, rejecting, not-accepting and eating. The sensory actions here are linked to the mouth (speech), eyes (look for) and brain (mind activity of hating, choosing, not accepting, spurning).

Seeing the body as object, another line of analysis can be followed. The types of bodies depicted in this poem differ from

\footnotetext{
5.Time is also important. Wisdom was calling and calling again. They suddenly change their movement from inside to outside. The issue of having auddenly change their moveme from inside to outside. The issue ag having a choice is also important. The deed-consequence nexus' (Loader 2014:99) means that your choic automatically intends a specific result. You are to blame only yourself. The choice in the Garden of Eden was detrimental to the humans who chose to be disobedient.
}

the usual. What is strange is that wisdom's acts are depicted with third-person feminine verbs, but she acts in masculine

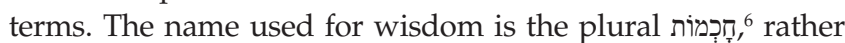
than the usual feminine ${ }^{7}$ of of the verbs are used. The first-person singular form used in the rest in 1:22-30 can indicate both femininity and masculinity. ${ }^{8}$ Generally, the prophet is a man and the third-person masculine form of the verb is used to describe his actions. Wisdom acts at those places where prostitutes (Gen 38:14, Ezk 16:25) and lady folly (Pr 9:13-18) operate. Fox (2008:97-98) remarks that it is 'incongruous and daring for the dignified Lady Wisdom to be frequenting such places and calling to men'. However, wisdom plays a masculine role in this passage. It acts exactly like a prophet does with the same authority. Wisdom's 'authority is manifested in her conduct and words' (Loader 2014:89). Authority is rather attributed to men than women. Wisdom acts as orator, talking like a prophet. The use of emphatic words like 'calls aloud', 'raises her voice' and 'cries' categorises her as someone of stature. The virtues wisdom offers are associated with the 'upper body with which males are predominantly identified' (Viviers 2005:883). Here we have 'inscribing of the male regulatory body' (Viviers 2005:883). According to Viviers (2005:884), wisdom here 'promotes male hegemony'. Wisdom takes initiative.

An interesting aspect of wisdom's 'maleness' is how her actions remarkably coincide with that of God. Wisdom's vocal abuse of those who disregarded wisdom 'is sometimes considered to imitate God's, for he too mocks his enemies (e.g. Ps 2:4, 37:13, 59:9) and shows contempt for all their powers and plans' (Fox 2008:101) ${ }^{9}$. Although wisdom is not any God-like entity, it is remarkable how wisdom's scolding of fools draws on the images of the prophet and the maledepicted God. The difference is that God is the One who brings calamity, but wisdom only observes what happens to them. She is not the one who brings disaster. It comes by itself. Their disaster is the result of a created order of retribution.

One further remark is in order. The pouring out of thoughts

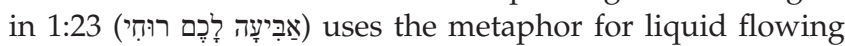
(Hifil nq'). This can probably point in the direction of sexual intercourse. The masculine body of wisdom ejaculates what it offers into the container body of the hearers to be conceived by them. What wisdom pours out like water is to be absorbed by the hearers, grown inside their bodies and made part of their being.

6.Loader (2014:92) discusses this morphological problem of wisdom's name in the plural, and concludes that 'the word clearly functions as a singular'.

7. Fox remarks that the plural form is also used in Proverbs 9:1, Psalms 49:4 and Sirach 4:11. It is not a 'plural of extension and intensity' (Fox 2008:96) as Toy thought, but 'a pl. form treated as a sg. because it refers to a single figure' (Fox 2008:96). 'The pl. forms of bînāh and tebûnāh function almost exactly' the same 'designating both a plurality of sayings and an abstract singular' (Fox 2008:96).

8.Fox (2008:97) reads Täronnāh 'shout' not as a feminine plural, but rather as thirdperson feminine singular.

9.Fox (2008:102) points out the similarity with how God acts: In Hosea 5:15, for example, God says that Israel will one day feel shame and seek him (šiher as in $\mathrm{Pr}$ $1: 28 \mathrm{~b}$ ) when they are in trouble (sar = sarah as in $\operatorname{Pr} 1.27 \mathrm{~b}$ ). God will accept this $1: 28 b$ ) when they are in trouble (șar $=$ șarah, as in $\operatorname{Pr} 1: 27 \mathrm{~b}$ ). God will accept this approach, whereas (according to Hs 5:6) if they seek God merely 'with their flocks and cattle' they will not 'find' him (mașa as in Pr 1:28b). God's refusal to respond when sought is also mentioned in, for example, Micah 3:4; Isaiah 1:15; and Jeremia 11:11. In a similar formula of reciprocity, God says, 'I spoke to you constantly, but you did not listen; and I called to you, but you did not answer' (Jr 7:13; cf. Jr 35:17; Zch 7:12). Eliphaz upbraids Job with a similar taunt: 'Call now. Will anyone answer you? And to whom among the holy beings will you turn?' (Job 5:1). 
The body (-ies) of the hearers plays a feminine role. In Proverbs 9:13-18, folly is personified as a woman sitting at her door inviting passers-by to come into her house. The hearers' bounded surface restricts them from moving outwards. The woman's body is more porous than that of the man. What wisdom pours out can be absorbed by the (womanly) hearers. Being aware of their (womanly) position, the hearers are inclined to close ranks and keep to themselves (cf. Viviers 2005:881; Berquist 2002:67, 80). Turned inwards to themselves, the simple ones love their own simple ways, the mockers delight in their own mockery, and the fools hate what can be known. The addressees are metaphorically indicated as self-lovers and self-destructors. They are marked by ignorance, arrogance and overconfidence (cf. Fox 2008:41). Like woman folly in Proverbs 9:13, who is undisciplined and without knowledge, they also act foolishly. They are like a self-contained woman having only eyes for herself looking into the mirror. She is unwilling to open up to wisdom's

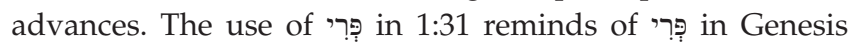
3:2-6. Eating the fruit in the Garden of Eden initiated by the feminine Eve led to the catastrophe of being banned for life from the garden. Their own fruit is a negative metaphor for their own foolish ways. The result of their actions shows an 'intrinsic retribution' (Fox 2008:102). There is a 'behaviorconsequence nexus' (Fox 2008:102). They will suffer 'the effects of their own schemes and deed' (Fox 2008:102). They closed themselves for wisdom. Like the Lord had closed the womb of Hannah (1 Sm 1:5), the striking disaster, whatever form it took, forces the hearers into a disgraceful position similar to that of a women who is scorned because she has no children (cf. the issue of honour and shame). Their womb cannot conceive any longer. Wisdom ceased to pour out to them what was initially offered to them. This causes them to change their strategy. Like the adulteress in Proverbs 7:8-15, the addressees now move out into the street. They become restless, no longer willing to stay at home, 'now in the street, now in the squares' (Pr 7:12). Like woman folly (Pr 9:13-18) who sits outside her house on a seat at the highest point of the city, they go out to call upon wisdom like wisdom initially תָּ upon them. They present themselves like a harlot to wisdom to receive the poured out semen that can bring life to them. However, wisdom is unwilling, like Onan was with Tamar to procreate new life (Gn 38:8-10).

\section{Summary}

This brings me to Jindo's third step to clarify and extend the conceptual information to ancient culture, in this case wisdom theology. The Gestalt of these clustered metaphors are cultural metaphors for the internalisation of wisdom. The 'cross-metaphorical correspondences' (Lakoff \& Johnson 2003:98) or 'conceptually integrated configuration' (Jindo 2009:226) points to internalised wisdom. The events from the everyday domains of speech and human hearing are used to talk metaphorically about the corresponding cluster of concepts in the metaphorically defined domain of the theology of wisdom (cf. Lakoff \& Johnson 2003:53). The configuration established by the metaphors for speaker and addressees is part of a larger metaphorical system that serves the 'complex purpose of characterising the concept of an argument in all of its aspects' (Lakoff \& Johnson 2003:106). The non-physical (wisdom as abstract) is conceptualised in terms of the physical (people talking, listening and reacting). But wisdom is no mere abstract or idea. It is something that is to be internalised in the life of people. It is something that must enter one's heart (Pr 2:10), become part and parcel of one's being. In terms of Proverbs 1-9, it is the same as the fear of the Lord: a living all-encompassing relationship with God day by day. Without wisdom life becomes unbearable, barren. Wisdom conceived becomes a living entity alive in men.

\section{Acknowledgements Competing interests}

The author declares that he has no financial or personal relationship(s) that may have inappropriately influenced him in writing this article.

\section{References}

Berquist, J.L., 2002, Controlling Corporeality: The Body and the Household in Ancient Israel Rutgers, University Press, New Brunswick.

Embodied cognition, Wikipedia, viewed 25 June 2018, from https://en.wikipedia.org/ wiki/Embodiedcognition.

Fox, M.V., 2008, Proverbs 1-9: A new translation with introduction and commentary, Anchor Bible 18A, Yale University Press, London (Logos Edition).

Harquail, C.V. \& King, A.W., 2010, 'Construing organizational identity: The role of embodied cognition', Organization Studies 31, 1619, viewed 28 June 2018, from http://journals.sagepub.com/doi/abs/10.1177/0170840610376143.

Jindo, J.Y., 2009, 'Toward a poetics of the Biblical mind: Language, culture, and cognition', Vetus Testamentum 59, 222-243. https://doi.org/10.1163/15685 3309X406659

Lakoff, G. \& Johnson, M., 2003, Metaphors we live by, The University of Chicago Press, London.

Loader, J.A., 2014, Proverbs 1-9, Historical Commentary on the Old Testament, Peeters, Leuven.

Tschacher, W. \& Scheier, C., 2001, 'Embodied cognitive science: Concepts, methods and implications for psychology', in M. Matthies, H. Malchow \& J. Kriz (eds.), Integrative systems approaches to natural and social dynamics, Springer, Berlin, Heidelberg. https://doi.org/10.1007/978-3-642-56585-435

Viviers, H., 2005, 'The 'body' and Lady Wisdom', OTE 18(3), 879-890.

Wilson, M., 2002, 'Six views of embodied cognition', Psychonomic Bulletin \& Review 9(4), 625-636. https://doi.org/10.3758/BF03196322 